\title{
Coming Back for More Quality Learning Experience
}

\author{
Mazni Saad*, Rosita Husain, \\ Wan Nurul Fatimah Wan Mohamad Nawi, Nafiza Mahyuddin \\ Faculty of Business and Accountancy, \\ Universiti Selangor, Shah Alam, 40000 Selangor, Malaysia \\ maznisaad@unisel.edu.my
}

\begin{abstract}
This preliminary study investigates students' expected learning experiences that determine their return to the same university for further studies. A cross-sectional analysis was done on 190 undergraduate students in a private institution of higher learning. Their opinions were sought regarding the present quality of services offered by the university. Their concern was for quality teaching, lecturers and facilities, and especially course fees, technology, and support systems. The study highlights the need to look again at some of the students' major complaints, which could guarantee their return to the university's doorstep.
\end{abstract}

Keywords: Satisfaction; learning experience; quality services; private university; Malaysia.

eISSN 2398-4279 @ 2018. The Authors. Published for AMER ABRA cE-Bs by e-International Publishing House, Ltd., UK. This is an open access article under the CC BY-NC-ND license (http://creativecommons.org/licenses/bync-nd/4.0/). Peer-review under responsibility of AMER (Association of Malaysian Environment-Behaviour Researchers), ABRA (Association of Behavioural Researchers on Asians) and CE-Bs (Centre for EnvironmentBehaviour Studies), Faculty of Architecture, Planning \& Surveying, Universiti Teknologi MARA, Malaysia.

DOI: https://doi.org/10.21834/ajqol.v3i12.138 


\subsection{Introduction}

In a dynamic and competitive environment, a private institution of higher learning has to sustain and strengthen its competitive perimeters by ensuring that its main customers are happy and satisfied and would come back for further studies. This makes the voice of the students the one selling point that gives the university a competitive edge.

A university's main income largely comes from student fees, but the growing presence of new private universities poses a great challenge - in retaining students for continued studies every semester. Students also want to perform better every semester so that they can request a reduction in scholarship funds they owe funders during their foundation program. When this happens, many private universities will lose existing students who can now further their studies in any recognized public university that offers a "good brand," at cheaper fees.

Therefore this study wants to learn about quality learning that would bring the greatest satisfaction to every student so that they would come back to the same university for more.

\subsection{Literature Review}

\subsection{Satisfaction}

Private higher learning institutions create the best learning environments that foster excellent students who are also loyal to the organization. While it ensures that students' excellent academic performance is prioritized, it wants students to be happy and satisfied with their new learning experience. Satisfaction here refers to feedback from a consumer resulting from the accomplishment of some expectations (Oliver, 2010). It is an evaluation of a product or service or the product or service itself providing an acceptable level of consumption related to under or over fulfillment. It also refers to a consumer's statement of quality experience while using or after using a product or service in comparison to their expectations before consumption (Stoica, Radu, Dobrescu, and Orzan, 2014).

Satisfaction from a customer's perspective (Ene and Özkaya, 2014) compares expectations obtained from their expectations before an experience. This means customers will be satisfied when their experience meets expectations and will be delightful when the experience is above expectation. Therefore, satisfaction can only be obtained after consumption as a result of evaluating the performance of the product or service before and after the service has been performed. The most common among definition is that emotional reaction influences consumer satisfaction, and that thoughts and expectations towards the perception of the product or service performance result from consumer experience at certain points of time.

\subsection{Entities in Higher Education Institutions}

Today, higher education institutions realize that their entities represent a business-like service industry. Their job is to attract students by meeting or even exceeding the needs of their students (Gruber, Fuß, Voss, \& Glaeser-Zikuda, 2010). It has also resulted in scholars refocusing their research towards measuring students' learning experiences in universities. Recent studies by Hanssen and Solvoll (2015); Butt and Rehman (2010); and Hussain et al. 
(2014) highlight the importance of facilities, technology, lecturers' expertise, management and interpersonal support to ensure greater students' satisfaction.

\subsubsection{Facilities and Technology}

Facilities and technologies are fast becoming important entities in any education system. Higher learning institutions focus on these two variables and adopt them as part of their market-oriented strategies that differentiate them from their competitors (Gruber, 2010). Hanssen and Solvoll (2015) investigated satisfaction towards facilities among small universities in Norway. Their survey of 5232 (28\% response rate) reveals that reputation, cost, job prospects, the host city, study hall, group work, auditorium, social areas, and computer access greatly affected students' satisfaction. A similar investigation in Thailand studied factors that influence students' intentions to study at universities by adopting the "student-as-customer" concept. From 318 responses, the SEM AMOS shows that all variables were supported except for ease of course achievement towards attitudes.

Therefore, recent studies of small and large institutions of higher learning indicate that students' expectations are high and both structure and infrastructure are equally important in satisfying and influencing their choice of a university. Students who are shaped by their positive experience of "campus life," and studies develop a real perception of their learning experience and would normally provide a good testimony that could attract potential students to further their studies at the university. Armed with the most powerful word-of-mouth communication for a marketing tool, the chance that current students would further their studies at the same university would be very high.

Moreover, online facilities and technologies are recognized as important tools in motivating students (Oliver, 2010; Yuan \& Powell,2013). According to Yuan \& Powell cited in Belanger and Thomton (2013), they (1) support lifelong learning or understanding of subject matter, (2) are fun and entertaining and provide a social experience, and intellectual stimulation, (3) are convenient and (4) allows one to experience or explore purpose.

\subsubsection{Lecturers' Expertise}

Another university asset with a major influence on overall student satisfaction is lecturers' expertise. The study by Butt and Rehman (2010) on 350 students from different private and public universities in Pakistan measured the influence of teachers' expertise, courses offered, learning environment and classroom facilities on student satisfaction. All the attributes had a significant and positive impact on student satisfaction although at varying degrees. The authors concluded that lecturers' expertise is the most influential factor among all of the variables and therefore deserves special attention from policymakers and institutes. A similar study by Hussain, Jabbar, Hussain, Rehman, and Saghir (2014) compared students' satisfaction towards both academic and non-academic facilities in the universities of Azad Jammu and Kashmir. Their dissatisfaction towards facilities was not comparable to that found among students in several universities of Punjab which revealed that teachers' expertise was significant in one faculty but not the other. This study also showed that both faculties were satisfied with other variables like the library.

Martirosyan (2015) studied factors contributing to student satisfaction in nine public and 
three private Armenian higher institutions located in different rural and urban areas. Students from private institutions reported a significantly higher satisfaction level than their peers at public institutions. It was also concluded that overall lecturers' expertise had the most dominant influence on students' quality learning experience.

\subsubsection{Management and Interpersonal Support}

Support from university administrators is another variable influencing student satisfaction. Oscar, Kara, and Kaynak (2005) studied the determinants of business students' satisfaction and retention level in South Central Pennsylvania higher education institutes. When Herzberg's two-factor theory was applied, a symbolic relationship was found between the student, higher learning institution, and society which enhanced student satisfaction and retention. It also created a model of student satisfaction and intention that incorporated 18 independent variables representing six higher-order dimensions: faculty, staff advising, classes, student partial college experience, satisfaction, and intentions. Support management, such as staff advising provides students information and counseling that enables them to proceed with higher learning efficiently. A path analysis incorporating a set of independent variables and self-reported experiential assessments was done on 160 business undergraduates and concluded that students with positive experience were satisfied with the university compared to those who were not.

Another study by Gruber et al. (2010) examined student satisfaction with services using a combination of lecturers and students as their respondents. Fifteen quality dimensions, covering most aspects of students' life including administrative and student services, the atmosphere among students, the attractiveness of surrounding city, computer equipment, courses, library, lecturers, lecture theaters, cafeteria and others were discussed. A positive relationship between student satisfaction and a stable person-environment was revealed.

Present literature indicates that students were satisfied with moderate service quality and the university's conducive learning environment. Management support influenced students' expectations, which contributed to a positive perception of the university thus increasing the chances of students remaining in the same university to further their studies.

\subsection{Methodology}

This preliminary study investigated students' quality learning experience in the satellite campus of a private university in Selangor. 190 final semester students who completed a course in Quality Management were selected from three bachelor programs (Marketing, Business Management, and Human Resource Management). A non-probability sampling was adopted for the survey and was operationally favorable and relevant because students were familiar with aspects of quality and could relate theory to real cases. Also, all the programs selected comply with the Malaysian Qualifications Agency (MQA) requirements and are responsible for quality assurance practices. As such, this study offers only a descriptive analysis which focuses on entities mostly preferred by the students.

This study has several limitations. Firstly, a cross-sectional analysis of the sample was done at the same time to identify the final year students, whose opinions were then sought 
regarding the present quality of services offered by the university. The students answered the questions but limited to only four points based on the existing situation of the university. One other possible limitation is that the campus has reached maximum capacity and could not accommodate more students. Also, repair work was being done to all air conditioners in the buildings making the class atmosphere quite hot and uncomfortable due to a large number of students (40-60) placed in each class at one time. Finally, this investigation is a case study of only one private university in Selangor.

\subsection{Findings}

\subsection{Overall Findings}

Figure 1 shows that more than $60 \%$ of the responses were from students enrolled in Human Resource Management. The second largest (26\%) was from Business Management followed by Marketing (13\%). They were mainly female students $(66 \%)$.

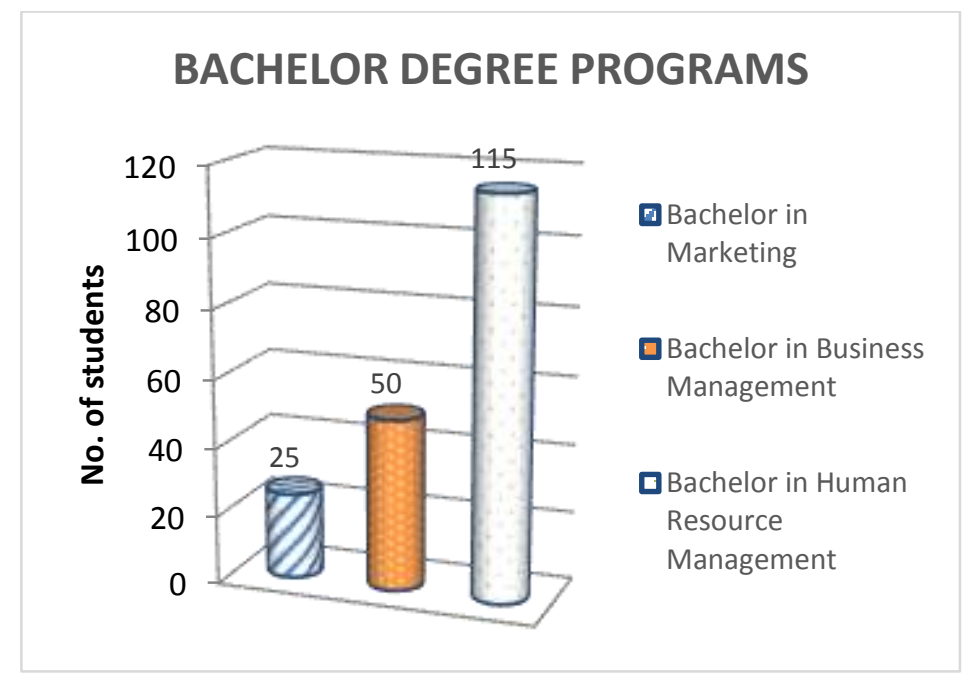

Figure 1: Bachelor Degree Programmes involved in the study

There were concerns about the quality of teaching, lecturers, and facilities but more so with course fees, course accreditation, technology, and support systems. Figure 2 presents the students' preferred entities. 


\section{Quality services for increasing satisfaction}

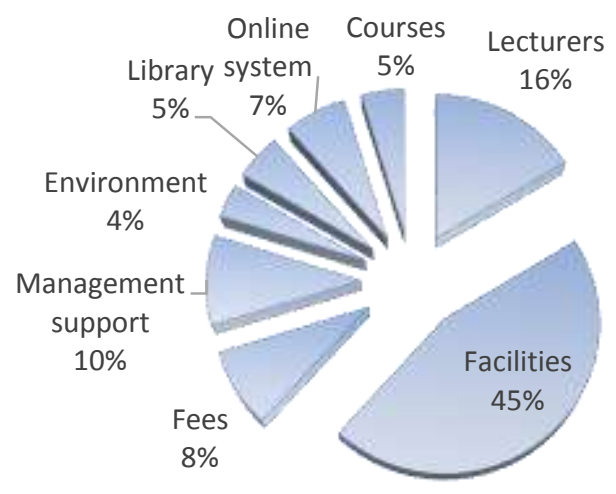

Figure 2: Preferred Entities

\subsection{Preferred Entities}

Figure 2 shows facilities (45\%) as the most preferred entity. This refers to a clean, calm environment complete with cheerful and colorful buildings that would be attractive to students who have to spend at least three years studying a registered course (R0691). This desired environment could be possible according to R1641 and R6881 with well-maintained air conditioning in every classroom, a clean cafeteria, gymnasium, bigger library space and more parking lots. There was a critical need for well ventilated and conducive classrooms equipped with air conditioning that would encourage students to participate actively in class. This comment was made about existing classrooms in the university which were too small to accommodate 40 to 60 students. To the students, a good study environment also means classrooms have proper tables and chairs and are up to date with the latest technology to enhance students' learning focus. In addition to a clean and healthy environment, students want the university to provide an environment-friendly campus by immediately removing potential distractions that de-motivate students from concentrating on their studies. Another important factor that impacts students' satisfaction level is feeling safe and secure on campus. Thus safety measures like fire management and CCTV were essential to a positive learning experience.

The second preference is teaching environment. $16 \%$ responses mentioned lecture styles and taught aids that fulfill their overall satisfaction of university learning. Their preferred lecture mode uses visuals more than words as it helps them to "stay focused in class" and remember lectures better. R2441 suggested creative and innovative teaching approaches like employing technologically advanced tools to make learning fun and maximize quality teaching, thereby increasing satisfaction in learning. There was also a preference for 
experienced lecturers who can deliver knowledge as well as share real working experiences (R1721). It was thought that permanent staffs were committed to spending more time with students, particularly during consultation hours. Therefore, R7521 felt that reducing the number of part-time lecturers could solve the apparent "lack of commitment" attitude. It was also felt that the university's management should make better use of the yearly feedback that students make on lectures, particularly their complaints. Students also expect their yearly comments on lectures and lecturers to be reviewed and used as the basis for some action to be taken by the management.

Another important influencing factor to satisfaction is administrative staff with excellent communication skills. To the students, the main role of administrative staff is not only to monitor them, but also to have a good relationship with them (R2651). Also, 10\% of the students expect the administrative staff to give them useful information and treat them fairly (R1241). Although they realize that they make some of the mistakes, they still expect to be continuously guided with courtesy. According to R0671, They also want the administrative staff to be willing to deal with them comfortably as it was the only access they have to solve problems with the university.

This study highlights concerns about high course fees. Students are loyal to what they consider a reputable university but would like to be rewarded in the form of fee reduction. After all, many current students chose the university in the first place because of the cheaper fees offered compared to other private universities (R352). They believed they would be "more passionate and efficient learners" when affordable fees come with excellent facilities and a good learning environment (R1451, R1621).

The study recorded only a $7 \%$ out of campus student accessibility to the university's online system. Therefore, improving students' learning experience, in this case, would mean upgrading the system to ensure "trouble-free access" for students. As for library needs, students wanted more reference materials, more rooms for discussion and more personal computers. Comments were also directed towards a more convenient and student-friendly e-registration procedure (R0691) which could increase satisfaction towards the university (R2441). A similar user-friendly registration procedure for paying examination fees was also mentioned.

Finally, Figure 2 refers to other preferred entities: existing courses, library, and environment. There was a call for more Ph.D. qualified lecturers to write manuals and books (based on lecture notes, powerpoint slides, and handouts) for classroom use as this would help reduce the high cost of buying textbooks and references already in the market (R1358). This study concludes that all the preferred entities shown in Figure 2 play a vital role in influencing students' satisfaction though in varying degrees. It is believed that the university in this preliminary study would have to deal with the issues brought up by the students to ensure their return for more academic pursuits.

\subsection{Discussion}

This section discusses the four quality services consistently brought up by the participants of this study: facilities and technology, lecturer's expertise, management support and student- 
university relationship, all of which contribute to students' quality learning experience. University facilities were found most influential in determining satisfaction which is similar to the $34 \%$ variance found by Hanssen and Solvoll (2015). Also included in the list of facilities are course fees. Facilities have become a selling point for many universities, so it is essential that the best facilities be portrayed and marketed well to attract both the students and their parents.

The second quality service is academic expertise which is often realized in a well-planned and well-delivered academic program. Lecturers have a big role to play in attracting the best students to the university. They bring to class cutting edge teaching methodology and will become a point of satisfaction for many students (Arif, llyas, \& Hameed, 2013). Small, Dowell, and Simmons (2012) and Kim, Pederson, and Baldwin (2012) demonstrate how the adoption of online learning is more effective and immediate when posting announcements and new materials, thus initiating synchronous and asynchronous communication with the students. Students perceive the use of social media such as e-mail or WhatsApp as relevant in today's education set-up. As such, lecturers are constantly expected to upgrade existing skills and learn new ones so that they can share and help students achieve desired grades in examinations.

Thirdly, students wish for a cordial relationship with the university's administrative staff and want to be treated as customers. Finally, there is a need to relook again at some of the major student complaints, especially those related to existing fees. The findings also indicate that it is imperative for a private university to ensure continuity of its business by improving its services. This finding is consistent with those of Burge et al. (2014) which found tuition fees to be the key motivating factor for a students' choice of a university, locally or overseas. As such, aggressive initiatives must respond to the dynamic economy, where the education industry is today a booming market force. With course fees becoming a primary source of income for a university, it needs to develop a long-term relationship with its present students instead of depending on new ones. This new relationship would reduce cost and generate more income for the university.

The university should establish and enhance a strong bond with the students. When all the expected entities are fulfilled, students will have a strong belief and a positive perception and attitude of the institution. This will eventually create the much-needed loyalty and willingness to recommend the institution to others. After all, loyalty, as mentioned by Fernandes, Ross, and Meraj (2013) is overall program satisfaction ( $\beta=0.507)$ consisting of good teaching quality, organization and management of the program, academic support, and satisfaction with services and facilities $(\beta=0.248)$ that will contribute to student loyalty and their recommendation to others.

\subsection{Conclusion and Recommendations}

This study concludes that students' learning experience is crucial, and the ideas of these students must be taken into consideration for continual improvement. In sustaining a higher education business, it is recommended that a private university conduct research on students' 
satisfaction to seek a list of variables that can make students happy and satisfied. Subsequently, students will also rate services and management to analyze their level of satisfaction as customers.

\section{Acknowledgement}

This research would like to dedicate special thanks to Universiti Selangor and specifically all lecturers and students of Quality Management (PMS3383) in semester 41534 for their cooperation.

\section{References}

Arif, S., llyas, M., \& Hameed, A. (2013). Student satisfaction and impact of leadership in private universities. The TQM Journal, 25(4), 399-416.

Burge, P., Kim, C. W., Rohr, C., Frearson, M., \& Guerin, B. (2014). Understanding the Impact of Differential University Fees in England. RAND Europe.

Ene, S., \& Özkaya, B. (2014). A Study on Corporate Image, Customer Satisfaction, and Brand Loyalty in the Context of Retail Stores. Asian Social Science, 10(14), 66.

Gruber, T., Fuß, S., Voss, R., \& Glaeser-Zikuda, M. (2010). International Journal of Public Sector Management, 23(2), $105-123$.

Hanssen, T.-E. S., \& Solvoll, G. (2015). The importance of university facilities for student satisfaction at a Norwegian University. Facilities, 33(13/14), 744-759.

Hussain, S., Jabbar, M., Hussain, Z., Rehman, Z., \& Saghir, A. (2014). The Students' Satisfaction in Higher Education and its Important Factors: A Comparative Study between Punjab and AJ\&K, Pakistan. Research Journal of Applied Sciences, Engineering, and Technology, 7(20), 4343-4348.

Kim, H. J., Pederson, S., \& Baldwin, M. (2012). Improving user satisfaction via a case-enhanced e-learning environment. Education and Training, 54(2/3), 204-218.

Martirosyan, N. (2015). An examination of factors contributing to student satisfaction in Armenian.

Oliver, R. L. (2010). Satisfaction: A Behavioral Perspective on the Consumer (pp. 383). Retrieved from https://books.google.com.my/books?hl=en\&lr=\&id=TzrfBQAAQBAJ\&oi=fnd\&pg=PP1\&dq=satisfaction+oliver+2014 \&ots=LoTxfVY7Ox\&sig=V254Fkox4gvrtqtB7gPcBLPso00\&redir_esc=y\#v=onepage\&q=satisfaction\%20oliver\%202 $014 \& \mathrm{f}=$ false

Oscar, W. D. J., Kara, A., \& Kaynak, E. (2005). Determinants of business student satisfaction and retention in higher education: applying Herzberg's two-factor theory. International Journal of Educational Management, 19(2), 128-139.

Small, F., Dowell, D., \& Simmons, P. (2012). Teacher communication preferred over peer interaction: Student satisfaction with different tools in a virtual learning environment. Journal of International Education in Business, 5(2), 114-128.

Stoica, I., Radu, A.-C., Dobrescu, A., \& Orzan, O. A. (2014). Modelling User Satisfaction of Medical Educational 
Saad, M. et. al. / Asian Journal of Quality of Life (AjQoL), 3(12) Jul / Aug 2018 (p. 23-32)

Services. Annales Universitatis Apulensis Series Oeconomica, 16(1), 229-238.

Yuan, L., \& Powell, S. (2013). MOOCs and open education: Implications for higher education. Retrieved from http://publications.cetis.ac.uk/2013/667 